\title{
Scholarship on Gender and Sport in Sex Roles and Beyond
}

\author{
Annelies Knoppers • Mary McDonald
}

Published online: 10 August 2010

(C) The Author(s) 2010. This article is published with open access at Springerlink.com

\begin{abstract}
In this paper we critically review how research on girls or women and sport has developed over the last 35 years. We use a post-positivist lens to explore the content of the papers published in Sex Roles in the area of women, gender and sport and examine the shifts in how gender and sport have been conceptualized in these accounts. In order to initiate a broader dialogue about the scholarly analysis of gender and sport, we subsequently explore ideas inspired by feminist theorizing that have dominated/guided related research in other outlets over this time period but have received relatively little attention in papers published in Sex Roles. We conclude by briefly making suggestions for further research in this area.
\end{abstract}

Keywords Sport · Gender. Theory

\section{Introduction}

Three years after its inception, Sex Roles published its first paper on the topic of women and sport. Since then Sex Roles has published more than 75 papers in this area. We

\footnotetext{
A. Knoppers $(\bowtie)$

Utrecht School of Governance (USG),

University of Utrecht,

Bijlhouwerstraat 6,

3511 ZC Utrecht, The Netherlands

e-mail: a.e.knoppers@uu.nl

M. McDonald

Department of Kinesiology and Health,

Western Program for Interdisciplinary Studies, Miami University, 204C Phillips Hall,

Oxford, OH 45056, USA

e-mail: mcdonamg@muohio.edu
}

have been asked to review research in the area of women, gender and sport as part of the commemoration of the 35th anniversary of the publication of Sex Roles. We are honored to be invited and have tried to meet this request in various ways in this paper. First, we use a post-positivist lens to look critically at what has been published in Sex Roles over the past 35 years and examine the shifts in how gender and sport have been conceptualized in these accounts. We then explore ideas inspired by feminist theorizing that have dominated and guided related research in other outlets over this time period but have received relatively little attention in papers published in Sex Roles. Our goal in this section is to initiate a broader dialogue about the scholarly analysis of gender and sport. We conclude by briefly making suggestions for further research in this area.

\section{Women, Gender and Sport in Sex Roles}

In order to understand the (shifts in) content and the type of topics that have received attention, we conducted a content analysis of papers in Sex Roles that explore organized sport and gender. Our search was not meant to be exhaustive but instead was designed to provide an overview and examples of general trends on the subject of gender, women and sport found in this publication. We chose to focus mainly on gender as related to women and not men in sport as this is the main focus of the majority of articles in Sex Roles and until recently this has been the main thrust of research published beyond the pages of Sex Roles as well. We chose organized sport as our focus since that is an area where gender is formally institutionalized creating women's and men's competitions and since such research is more easily demarcated from investigations that focus on related themes such as body image, fitness or physical activity without a 
specific context. Using several combinations of the keywords "athletes," "athletics," "gender," and "sport" we found 75 empirical research articles published between the inception of the journal and December 2009. We made an inventory of these articles noting: names of authors; purpose of the study; definitions of gender, social class, age, educational level, and race/ ethnicity; locale of the study (when mentioned); theoretical approach; methodology used including (when appropriate) how variables were defined and measured; and the main finding. We used this inventory to reflect on the contents of Sex Roles with respect to the topic of women, gender and sport.

In 1978 Sex Roles published its first paper with a focus on sport (Greendorfer 1978a). The rate of publication since then reflects an increasing interest in the area of sport and gender and/or in publishing in Sex Roles. Twenty-two papers were published in the first 25 years of the existence of Sex Roles and more than double that amount (53 papers) in the last 10 years (2000-2009). We now examine this content in greater detail by critically exploring who and what was studied and how gender was theorized.

\section{Researching Women, Gender and Sport}

\section{Populations Studied}

The two most common populations that were studied consisted of high school students and college students. Most authors (44 papers) used only college students as subjects while a much smaller number (15) investigated high school students only. Several looked at adults in a variety of roles in the sport context such as athletes (e.g., Hendy and Boyer 1993), sport administrators (e.g., Sagas and Cunningham 2004), and parents (e.g., Sartore and Cunningham 2009) or had no subjects at all such as in media content analyses (e.g., Hardin et al. 2005). Since many researchers work at universities this choice or preference for college students as subjects is not surprising. We note however, that with the exception of Greendorfer (1978a), no study focused specifically on social class. Yet the number of studies using college students only suggests a class bias.

The majority of the papers seemed to implicitly assume certain universal characteristics (American, White, heterosexual) of participants while explicitly assuming (and searching for) difference across gender and/or athletic status with an occasional use of socioeconomic status and/ or race/ethnicity/nationality of participants as independent variables as well. Exceptions to these assumptions were not confined to a specific decade (e.g., Hendy and Boyer 1993; Rao and Overman 1984; Shaffer and Wittes 2006; Young and Bursik 2000). Overall however, authors seemed to assume that the population and cultural context under study was the USA and was so self-evident that it was not worthy of mention. Countries were only mentioned when studies were conducted outside of the USA such as in the Netherlands (e.g., De Bruin et al. 2009), England (e.g., Fielding-Lloyd and Meân 2008), France (e.g., CoulombCabagno et al. 2005), Sweden (e.g., Koivula 1999), Norway (e.g., Klomsten et al. 2004) and Turkey (e. g. Koca et al. 2005). Possibly a research emphasis on gender roles in conjunction with sport is a practice that is more firmly embedded in American research culture than in other cultural and/or national contexts. This US-emphasis also reflects the fact that Sex Roles originally developed as an outlet for research mainly related to the US, with a more international focus emerging in recent times. Sex Roles now requires that all published articles specify the national locale of the research (Frieze and Dittrich 2008). It is also important to note that whether the studies explored European or North American sport, the race and/or ethnicity of the participants were seldom mentioned and thus whiteness seemed to be assumed. Rao and Overman (1984) were the only authors who focused specifically on Black female athletes and nonathletes while Greendorfer (1978a) not only wrote the first article published in Sex Roles on gender and sport, but as previously noted was also the only author to place socioeconomic status at the center of her investigation.

Researchers who focused on gender and sport, especially in articles printed prior to 2000 , seemed to associate the topic with women. During that time, four times as many papers (20) focused on females than on males. The remaining papers compared results across gender. In the 35 years that Sex Roles has been in existence, athletes were compared with nonathletes in a little less than half of the articles published in the area of gender and sport (e.g., Miller and Levy 1996), while nine papers focused on athletes only (e.g., Russell 2004). By failing to specify and investigate important demographic characterizations as well as important contexts influencing participants, scholars subtly assume that gender is salient in isolation from other social relations. Thus they may implicitly legitimize (American) White heterosexual men and women as the norm, marginalize differences within those groups and make other groups invisible as well.

\section{Levels of Analysis}

In order to make sense of what has been published in Sex Roles, we apply the concept "levels of analysis" that has been used in other feminist reviews regarding the changing state of scholarship about gender and sport (see for example, Birrell 1988; Hall 1988, 1996; see also Connell 2005; Messner 2009). These scholars conceptualized gender at three levels: individual/ categorical, institutional/ distributive and symbolic/ ideological/ relational. Research at the individual/categorical level argues that male and 
female are self-evident categories and tends to use quantitative methodologies to study differences between males and females while attributing any found differences to innate (often biological or psychological) traits and/or socialization. Institutional/ distributive research on the other hand, looks at how resources such as sponsorships, media coverage, participation possibilities and jobs in sport are distributed between men and women. Gender differences are attributed to structural inequalities in access to resources and opportunities (Kanter 1977). Symbolic/ideological/ relational research assumes that

sporting practices are historically produced, socially constructed, and culturally defined to serve the interests and needs of powerful groups in society. Sport therefore, is seen as a cultural representation of social relations and here includes gender, class, and race relations. (Hall 1996, p. 11-12)

This latter approach tends to rely on the use of qualitative methodologies to help researchers gain insight into the ideologies and relations of power that underpin sport practices and discourses about (those involved in) sport. All three levels of analysis are represented in the papers on gender and sport in Sex Roles.

The majority of the 75 papers, especially those published prior to 2000, focused on the individual level of analysis. Researchers compared male and/or female athletes/nonathletes using social-psychological constructs such as gender roles (e.g., Colker and Widom 1980; Ross and Shinew 2008), identity (e.g., Franzoi and Kleiber 2007; Young and Bursik 2000), body image, ability and self esteem (e.g., Marsh and Jackson 1986; De Bruin et al. 2009), socializing agents (e.g., Desertrain and Weiss 1988; Greendorfer 1978a; Weiss and Barber 1995), attribution (e.g., Croxton and Klonsky 1982; Hendy and Boyer 1993), locus of control (e.g., Kleiber and Hemmer 1981) or a combination of these topics. In general this research showed that regardless of sport, female athletes scored higher than nonathletes on these measures. This research thus served to counter mythological and popular beliefs about the potentially detrimental effects of sport participation on girls and women.

Several scholars also directly examined attitudes held toward females, and gays and lesbians in sport. For example, McDowell and Cunningham (2008) explored the attitudes of their sample of undergraduate US college students regarding physical contact by female coaches towards athletes concluding that these viewpoints were related to the subjects' attitudes towards women. They found that those holding more traditional beliefs (e.g. women as nurturers) were more likely to label a female coach striking a male or female athlete as inappropriate than those holding more progressive views regarding gender roles and expectations. Roper and Halloran (2007) reported that male athletes showed significantly more negativity towards gays and lesbians than female athletes while Sartore and Cunningham (2009) found that athletes and their parents held more negative attitudes towards lesbian and gay coaches than heterosexual coaches. In addition, female college students, university personnel and businesspeople were significantly more favorable about the use of nonsexist language in sport and nonsport contexts than were their male peers (Parks and Roberton 1998, 2000).

Twenty-one papers paid attention to "sex roles" and usually with the use of a standardized scale (e.g., Burton et al. 2009; Colker and Widom 1980; Shaffer and Wittes 2006). Early research often characterized this line of research as "sex roles" before moving to the more contemporary term gender roles. (To aid in the ease of readability and to recognize the more contemporary language in this review we use the term "gender roles" unless quoting an original source.) Often this focus on gender roles - or the social norms and expectations of each gender-was combined with other topics such as body image and self-ascribed physical concept (e.g., Klomsten et al. 2005). The notion that type of sport influences the ascribed gender role and/or attitude was a noticeable part of much of this research. Here, the type of sport studied tended to be defined with the designations of masculine or feminine. Subsequent gender typing of sports resulted in labels such as "sex appropriate" and "sex inappropriate" (i.e. women participating in sports labeled as masculine) and its relationship to gender typing of individuals (see for example, Harrison and Lynch 2005; Hoferek and Hanick 1985; Matteo 1986, 1988; Wrisberg et al. 1988). The prevailing assumption of this line of research was that gender labeling of sport influences other phenomenon including gender roles, attitudes towards women, identity, body image, self esteem, etc. In general, more female athletes than nonathletes were classified as androgynous while more female nonathletes than athletes were categorized as feminine. No evidence was found that female athletes, regardless of sport, experienced a significant amount of role conflict between their role as an athlete and as a girl/ woman. The results of this social-psychological based research again countered popular beliefs - in this case that women athletes were masculinized through their sport participation, especially in sports that were gender-typed as masculine, and that these athletes had to cope with role conflict. In short, based upon the results of the inventories used in each study, female athletes were found to be psychologically healthy.

Other research published in Sex Roles focused on gender and sport at the institutional level. Such research usually employed quantitative methodologies such as content analysis to determine the gendering of media coverage (e.g., Cunningham et al. 2004; Hardin et al. 2005; Koivula 1999), This work repeatedly demonstrated empirically that women's sport received far less media coverage and that as a whole, the representations of women typically conform to dominant 
societal stereotypes and that those athletes judged as attractive or "heterosexy" were featured most prominently. Other work at the institutional level focused on the constraints to and accessibility of leadership opportunities (e.g., Cunningham et al. 2007; Sagas and Cunningham 2004; Whisenant 2003, 2008; Whisenant et al. 2005). This work consistently showed that women were under-represented in coaching and leadership positions in the vast majority of organized sport settings and that various dynamics ranging from homologous reproduction to inequitable opportunities to develop social capital combined to exclude many women. Other institutional level scholarship explored the sponsorship of women athletes and the relationship between the values assigned to women's and men's sports, intentions to buy tickets and the comparative costs of ticket prices (Cunningham et al. 2008; Hebl et al. 2004). The results of such papers also consistently showed that as a whole, men's sport enjoys significantly more financial clout and sponsorship support than does women's sport.

In the last 5 years several papers were published in Sex Roles that paid attention to the symbolic meanings/constructions of gender. Specifically, researchers used qualitative methodologies to explore underlying ideologies that may sustain, strengthen or challenge meanings given to gender and/or gender inequalities. They looked, for example, at the gendering of the discourses drawn upon in coaching education (Fielding-Lloyd and Meân 2008), at definitions of equity used by administrators, athletes and coaches (Hoeber 2008), at processes of exclusion in sport journalism, sport management and sport governance (e.g., Claringbould and Knoppers 2007, 2008; Claringbould, Knoppers and Elling 2004; Knoppers and Anthonissen 2008), paradoxes in constructions of athletic femininities (Krane et al. 2004) and constructions of sporting masculinities (Anderson 2008; Schrack-Walters et al. 2009). In general, the findings revealed that sport governance, coaching education and sport management continue to be sustained by assumptions/ ideologies that construct sport as a "male domain." Although more women participate in organized sport than ever before, and gender equity continues to be a goal at all levels of sport administration, too frequently the ideal candidate for a position is a person who is assumed to possess qualities that fit the image of a competent male administrator and /or coach. This work investigating the symbolic meanings and the social construction of gender is consistent with the assumptions of a good portion of the feminist research published in outlets other than Sex Roles. We discuss this research in greater detail in the next and subsequent sections.

\section{Theorizing Gender}

\section{Conceptualizing Gender}

Both the creation of the journal Sex Roles and the concerted push for more opportunities for women to participate in organized sport in the 1970s were part of the second wave of feminism. At that time, a popular notion in psychological research (Smiler 2004) and the broader society (Cahn 1994; Hargreaves 1994) assumed that labels for behavior and for gender had to "match" as it was assumed that "so-called cross-sexed behaviors and preferences (e.g. athleticism among females) indicated emotional disturbance or sexual deviation" (Hall 1996, p. 18-19). Conversely, good mental health assumed gender orthodoxy (Connell 2005). Popular and scholarly understandings of femininity and masculinity at that time defined them as bipolar attributes. These popular notions played a large role in legitimizing who could participate in sport in general and in which sport specifically. The fear that girls and women would be masculinized, especially if they participated in sports designated as masculine, received a great deal of attention in research published in Sex Roles. The underlying assumption of many of these studies reflected the prevailing popular fears of the time about sport functioning as a masculinizing agent for girls and women (Birrell 1988; Hall 1996). Since sport was widely constructed as a masculinizing activity, those defending or interested in the participation of women and girls drew upon existing studies and engaged in empirical scholarship to show the extent that this fear was ungrounded/inaccurate and/or that sport participation had a positive effect on female athletes.

Researchers in the 1980s increasingly critiqued this assumed bipolarity of gender roles and instead promoted the concept of psychological androgyny, which was perceived to be a gender role characteristic that combined both instrumentality (masculinity) and expressiveness (femininity). The use of scales that included the concept of androgyny provided a "solution" to popular and scholarly dichotomous conceptualizations. These scales inferred that the gender typing of roles and sport could be measured "more accurately." The scales also took the focus away from any possible "proof" of masculinization of female athletes that might emerge in research. As a result, the use of a bipolar conceptual model could be/were diffused. Since androgyny was assumed to be a healthy and desirable trait/ state for women to possess, they could be encouraged to participate in sport, and sport programs for girls and women could be justified.

The 1980s also saw a growing critique regarding the emphasis on the individual and institutional/distributive levels of research on gender and sport and their reliance on quantitative methodologies. We discuss feminist contributions to the analysis of gender and power more fully below, but here summarize four often-used arguments from feminist perspectives that served to critique both individual and distributive orientations (Birrell 1988; Connell 1987, 2005; Hall 1988, 1996; Hargreaves 1994; Messner and Sabo 1990). First, such research was seen as decontextualizing because of its "tendency to meticulously measure 
and compare male and female experiences, attitudes, and athletic performances without a broader contextual framework that situates these attitudes and actions in a theory that emphasizes process, change and power" (Messner \& Sabo, p. 8). Such comparisons suggest that inequality can be resolved by the proper socialization of women (and men) and, by ensuring equal opportunities and media coverage. These comparisons fail to question the realities and relations of power that create those attitudes and lack of opportunities as well as the need to use concepts such as "masculinity" and "femininity."

Second, the concept of gender roles and gender typed sports and activities used in these articles about women, gender and sport assumes normativity, that is, that everyone has similar understandings of masculinity, femininity and what specific attributes constitute "masculine" and "feminine" (Knoppers 1980). Since most of the papers published on gender and sport in Sex Roles have used quantitative methods, such roles/activities/ideas have already been defined for the participants. These normative definitions are then in turn (re)used to characterize and classify individuals and (sport) activities. Questions as to whose interests are embedded in such norms are usually ignored (Connell 1987).

Third, the use of the concept of gender roles defined in terms of a bipolar or quadruple classification also assumes and (re)creates biological dichotomies while serving to legitimate heterosexuality as an unquestioned framework for understanding gender and sport. While the words "females" and "women" were used to represent biological constructs, within this line of research the labels femininity and masculinity were based on societal assumptions and stereotypes of how females and males should behave (Birrell 1988). Connell (2005) contends that this conceptualization of gender roles falsely suggests that

being a man or a woman means enacting a general set of expectations that are attached to one's sex- the 'sex role'. In this approach there are always two sex roles in any cultural context, a male one and a female one.

Masculinity and femininity are quite easily interpreted as internalized sex roles, the products of social learning or 'socialization'. (p. 22; italics in original)

Bipolar conceptualizations ignore those whose gender expressions fall outside of these characterizations. Hall (1996) also critiques this reification of the biological dichotomy but additionally argues that the broader cultural preoccupation with the femininity of female athletes is synonymous with heterosexuality and homophobia. "The real issue behind so much attention to an athlete's femininity was the fear that she might be a lesbian" (p. 19). The focus on homophobia and sport has received considerable attention in North American and British scholarship perhaps reflecting the particular role homophobia may play in these sporting contexts.

Fourth, research without proper contextualization also assumes a universality of gender experiences. This ignores the ways individuals may be positioned differently within social hierarchies and how other social relations of power such as social class, race/ethnicity sexuality, ability and age additionally mediate experiences of sport. In other words, femininity and masculinity are not universal practices and the diversity of ways they may be enacted creates femininities and masculinities (Connell 1995; Smiler 2004). We outline the ways other scholars of sport have discussed the issues of both homophobia and "intersectionality" in greater detail below.

\section{Explaining the Emphasis on the Individual}

Although the mission statement of Sex Roles encourages submissions grounded in various social science disciplines, much of its published research on gender and sport is situated within psychology/social psychology possibly reflecting the interests of the first editors/editorial boards and the title of the periodical itself. Given this context, it is not surprising that the majority of the papers published in Sex Roles focus on the individual level of analysis. Not only are such papers congruent with the initial aim of the journal (Frieze and Dittrich 2010) but this focus also, reflects the political and research climate of the 1980s when several of these articles on sport appeared within Sex Roles. Connell (1987) points out that despite the availability of alternative feminist frameworks, the politics of academic/ research psychology strengthened the popularity of this individual approach in the 1980s as "the psychological establishment [was] very much concerned with scientificity, formal measurement and statistical proof" (p. 174).

Additionally, the papers that focused on the individual as well as the distributive levels of analysis and that utilize quantitative methodologies frequently reflect liberal feminist notions that "inequalities can be eliminated by breaking down stereotypes (changing attitudes) and giving women greater opportunities" (Connell 1987, pp. 33). In contrast to this liberal feminist approach that argues the need for more opportunities for women and girls in sport, other feminist researchers (see for example, Birrell 1988; Cahn 1994; Hall 1996; Lenskyj 1986; Theberge 1985) have instead argued the need to theorize the (lack of) involvement of women in organized sport and to question why sport participation was seen as a masculinizing activity in the first place.

A good portion of the early research on sport was also dominated by an "epistemological hierarchy that privileges positivist over postpositivist, quantitative over qualitative, and predictive over interpretive ways of knowing" (Andrews 2008, p. 45). The continued quantified use of 
the psychological constructs of femininity and masculinity may therefore also mirror (fixed) theoretical preferences of researchers (Smiler 2004) and perhaps more popular understandings of gender. These forces converged in a good portion of the research on gender and sport within the context of Sex Roles and may explain why research on women and gender roles (e.g., Burton et al. 2009; Greenleaf et al. 2009) in sport remains despite being critiqued by a number of scholars in the social sciences grounded in postpositivistic ways of knowing. The scholarship published in Sex Roles was not the only site for discussions about gender and sport, however. As we show below, the developments we have just traced in Sex Roles while representative of some trends and interests do not fully reflect the broader scope of the research in this area.

\section{Scholarship Beyond Sex Roles}

To characterize the ideas guiding scholarship published in venues outside of Sex Roles is a difficult task reflecting the global appeal of sport as well as the recent proliferation of scholarly writings about sport. Given the impossibility of succinctly characterizing the diversity of theoretical and conceptual underpinnings in this section we strategically review works more closely aligned with post-positivist sociological, feminist and interdisciplinary approaches rather than those primarily grounded in (social) psychology. Toward this end we use the occasion of Sex Roles 35th anniversary to generate broader interdisciplinary dialogues regarding the contemporary analysis of gender and sport. The first body of work that we discuss below eschews individualistic approaches by exploring the structural and relational aspects of sport, gender and difference while the second body of literature cited highlights poststructuralist and queer positions that question the extent to which structural analyses enacted via grand theoretical narratives are analytically useful. Instead poststructuralist and some queer writings expand the notion of the symbolic toward understanding the politics of representation and knowledge production (re)made through sport and diverse identifications.

It is important to recognize that our discussion of the boundaries between the different approaches outlined here is designed to fuel further conversations as overlapping conceptualizations mean that simple demarcations are impossible to make. Rather, we highlight our impressions of some key developments in the field particularly as articulated by members of the North American Society for the Sociology of Sport and the International Sociology of Sport Association. Much as with our analysis of the sport articles within Sex Roles, we acknowledge the interplay between approaches, summarize key insights and offer critique. Reviews offered by scholars such as Birrell (1988, 2000), Duncan (2006), Hall (1996), Hargreaves (1994), King (2008b), King and McDonald (2007), McDonald (2006), Scraton and Flintoff (2002) and Theberge (2000) inform this section and also serve as excellent references for those interested in an expanded discussion.

\section{Shifts in Feminist Frameworks}

\section{Applying Feminist Frameworks}

Birrell (2000) suggests that within North America and Europe, the 1960s and 1970s witnessed a burgeoning body of writings on women and sport, a good portion of which was written by women housed within departments of physical education. This work emerged from a growing cultural consciousness about broader gender inequities as well as the need to expand opportunities for women in a variety of social realms. Many of the authors of this early work were themselves actively engaged in professional organizations advocating for the expansion of women's sporting opportunities. Much as with the scholarship in Sex Roles, this early work on sport was largely descriptive (except see Felshin 1975; Hart 1972) and typically reflected psychological and/or social psychological worldviews while investigating such topics as gender roles, athletic role conflict, and personality and motivation traits of female athletes. Research about the role of socialization in the development of gender roles and in the making of athletes expanded this focus (see especially Greendorfer 1978b). As with the early scholarship on sport within Sex Roles, this broader body of sport scholarship largely conceived of gender as "a variable or distributive category rather than a set of relations sustained through human agency and cultural practice" (Birrell 2000, p. 64). This latter reconceptualization of gender would more fully emerge in the 1980s reflecting the concerted movement by some scholars toward more sociological and/or feminist orientations (Birrell 1988).

The annual meeting of the North American Society for the Sociology of Sport in Denver, Colorado in 1980 marked an important moment in the infusion of feminist reconceptualizations of gender and analyses into the study of sport. Not only did this conference provide a space for scholars from a variety of countries to discuss their common interests, but several presentations also engaged feminist concerns, themes and theoretical frameworks (Birrell 1988). No doubt aided by the emergence of the academic field of sport studies in Britain, Canada and the United States, throughout the 1980s scholars further utilized and honed feminist sensibilities drawing upon divergent feminist frameworks (e.g., Boutilier and SanGiovanni 1983, 1993). These writings helped bring into clearer 
focus the status of sport as a gendered activity. Consistent with sociological perspectives, the use of these feminist frameworks - including liberal, radical, socialist and Marxist feminism-helped shift attention away from individual levels of analysis that focused on the behavioral traits and motivation of female athletes. These feminist frameworks instead insisted on the acknowledgement of additional contexts from which to understand sport "in relation to broader systems of exclusion and mechanisms of control: pornography, abortion, rape, sexual assault, surrogate mothering, and the commercialization of beauty" (Cole and Birrell 1994, p. vii). Scholars of sport repeatedly demonstrated women's status as gendered outsiders while noting that "the acquisition of strength, muscularity, and athletic skill has always been empowering for men, whereas for women it is valued far less and in some cases is denigrated" (Hargreaves 1994, p. 146). Throughout the 1980s and into the early 1990s, liberal, radical and socialist feminist critiques served as the most visible forms of feminist analyses of sport. While liberal feminists continue to advocate for greater equity arguing for increased opportunities, at the core of radical and socialist frameworks was an understanding of sport and gender as not only social constructs, but also political constructs tied to broader social forces and the workings of power.

For example, building upon radical writings from within the broader feminist movement, scholars of sport explored the linkages between sport as a gendered activity and compulsory heterosexuality (Griffin 1998; Lenskyj 1986). Aligned with anti-homophobia activists these authors conceived of sport as a masculine preserve that too often privileges men over women and promotes heterosexuality through an obsessive preoccupation with femininity as embodied by female athletes. They additionally observed that women who transgress culturally prescribed ideals of femininity by engaging in masculine sports are subject to marginalization and homophobic ridicule. In this way compulsory heterosexuality is remade through sport. This process discourages female erotic and emotional bonding, while producing apologetic responses where women attempt to promote more feminine and/or "heterosexy" appearances while many sporting lesbians continue to live in silence and fear (Griffin 1998). More recent scholarship, especially that emanating from North American and Britain, has built upon this tradition to investigate the role of homophobia and compulsory heterosexuality within the realm of men's sport and has utilized queer theory to extend analyses (Caudwell 2006). We discuss the use of queer theory and sport further on in this paper.

Influenced by Marxist and Gramscian arguments about the limiting power of ideology and social structures, the 1980s also saw the emergence of scholarship demonstrating the pervasive and persuasive influence of gender ideologies. This type of analyses articulated a socialist feminist project as a corrective to existing class-based analyses of sport, which frequently down- played the significance of gender relations. While committed to integrating class and gender critiques of capitalism and patriarchy, much of the subsequent scholarship centered on establishing the ideological significance of sport as a gendered institution (but see Hargreaves 1994). This work, also linked to the emergence of cultural studies perspectives within sport studies, suggested the pervasive power of hegemonic masculinity and that the gender-segregated character of sport served to regulate sporting bodies relegating them to the ideological realm of the "natural" (Willis 1982). In this way cultural conditioning and the historical significance of sport as a male preserve are ignored (Messner 1988) as is the continuum of sport performances where women routinely outperform men (Kane 1995). Despite ongoing resistance and counter arguments, men's presumed physical superiority is promoted and frequently translated as "proof" of presumed male social superiority. In this way too frequently sport assists in legitimating dominant gender ideologies about the dichotomous "nature of the sexes" (Willis 1982). The sport media have played a key role in this process, trivializing female sporting accomplishment while frequently promoting themes of sexual difference, beauty and grace, and ambivalence (Duncan 1990). Discourses of sexuality have served as an important component of this framing helping to eroticize and (hetero)sexualize the female sporting body while constructing lesbians as a threatening presence. This perspective has infiltrated sport organizations in ways that suggest that women are commonly perceived as less suited for coaching and leadership positions (Shaw and Allen 2009) and paradoxically, that gender equity has been achieved (Hoeber 2007). This process is far from a simple imposition of dominant ideologies however, as resistance and alternative sport forms such as bodybuilding and women's rugby exist. These sports potentially challenge commonsense representations of gendered bodies thus demonstrating that both sport and female athletes have existed as ideological contested terrain (Messner 1988).

This line of scholarship investigating the pervasiveness of and resistance to gender ideologies continues and is perhaps most prevalent in the study of sport and the media as well as in the study of men and masculinities. In regard to the former, numerous scholars continue to discuss the under-representation of women in sport in relationship to their participation rates as well as the ways in which gender ideologies are remade, reinforced and/or challenged via announcer's commentary, dominant story lines, production techniques and corporate structures - the sum of which still cater to men's sport and the celebration of masculinity. What is still needed are more nuanced media studies that, for example, provide provocative conceptualizations to account for audiences' complex interpretations of and interactions with media texts (Duncan 2006). A good deal of scholarly energy devoted to the study of men and masculinity has worked with the concept of hegemonic masculinity to articulate the ways in which elite competitive 
sports such as basketball, baseball and football produce ideologies that privilege force, aggression and violence as values to be admired and emulated (Messner 1992; Trujillo 1995;Young and White 2000). However, this analytic perspective is not without its critics who question whether the concept has been judiciously applied to understand the complicated shifts in relations between men and women, and between men of different status positions related to race and class (Messner 1990). The growing commercialization and objectification of the elite male sporting body raises additional concerns about whether the concept of hegemonic masculinity is still analytically useful for understanding these contexts (Miller 1998).

\section{Critiquing Use of Feminist Frameworks}

Additional critiques similar to those offered in relationship to the Sex Roles articles can be made regarding the scholarship indebted to feminist frameworks. That is, the influence of these frameworks has allowed new insights to emerge while simultaneously - and problematically-promoting particular assumptions about universal characteristics (e.g., North American/European, White, and outside of the homophobia literature-heterosexual). For example, very little explicit attention has been given to the ways in which national and/global contexts structure gender relations and women's sport (but see von der Lippe 2002) although there is a body of literature that incorporates gender analyses into the study of men's sporting competitions and globalization (see for example Andrews 2006). While socialist feminist accounts do acknowledge that capitalist economic relations structure gender within a complex system of opportunity and reward, outside of the globalization scholarship and that of intersectional analysis (discussed below) very few contemporary studies offer a sustained focus that articulate the integration of gender and class; too frequently middle class status serves as the default position of these analyses. While an emerging body of scholarship has demonstrated empowering elements of lesbian sporting culture, a significant portion of this scholarship still focuses on the discriminating power of homophobia. Despite notable exceptions that are discussed in the next section, scholarship indebted to feminist frameworks has its limits in too frequently rendering subjectivities "in isolation from the process of racialization, gender normativity and capital accumulation through which they are constituted" (King 2008a, p. 8).

\section{Analyzing Intersectionality}

Since the 1990s a growing body of scholarship has attempted to explicitly rectify the concern that gender is often conceived in isolation from other interacting forces and thus attention to intersectionality is now more common in the sport studies literature than ever before. First coined by feminist legal scholar Crenshaw in the 1980s, the concept of intersectionality subsequently gained greater visibility through Black feminist theories such as those articulated by Collins (1990). Crenshaw's (1991) original observations documented the ways in which both the law and broader social movements typically theorized gender apart from race thus ignoring women of color's experiences as worthy of interrogation. In contrast, the importance of intersectionality is the recognition that powerful forces such as sexism, racism and classism are not independent of one another but are interacting forces. This (re)imagining of gender within a matrix of social relations accounts for a complex, shifting social order that impacts people's experiences within and beyond sport in divergent ways.

As previously noted early attempts at conceiving of gender as connected to other social relations was initiated by scholars who recognized that gender relations were intertwined with class relations; and in the case of radical feminist and anti-homophobia activists, sexuality. In too many cases this work failed to take race into account in meaningful ways and thus the impetus for securing more robust analyses of the interactions of power was advanced by scholars committed to utilizing critical race theories as well as Black, Indigenous and Chicana feminist sensibilities in order to rethink activist practices and theoretical discussions. This important development is also an acknowledgement of the pervasive whiteness of sport studies scholarship and accounts of the feminist movement. The voices of women of color have never been absent from sport and/or from the broader feminist movement, although scholarship and popular accounts too frequently have rendered their contributions and achievements invisible by positioning gender as the center of attention. This is problematic to those committed to critical reflection and analyses as "gender is only one part of an interconnected matrix of power relations which also includes relations of class, race, sexuality, religion, age, etc." (Birrell 2000, p. 65). Thus conceived, "neatly separating gender out of the matrix can happen only theoretically, and, through ignorance and neglect, this strategy does violence to those other oppressive relationships, such as race and class" (Birrell 2000, p, 65).

Scholars are increasingly addressing these omissions by focusing on the impact of ideologies of race, gender, class and sexuality (among other relations) on the experiences of Black female college athletes in the US (Corbett and Johnson 1993); discourses of the WNBA (Banet-Weiser 1999); football (soccer) in Britain (Scraton et al. 2005); Latina softball players (Jamieson 2005); use of city spaces by runners (van Ingen 2003) and representations of iconic athletes such as golfer Nancy Lopez (Jamieson 1998) and 
tennis stars Venus and Serena Williams (Douglas 2005). An emerging component of the intersectional focus centers on theorizing the experiences of Muslim women in sport (e.g., Hargreaves 2000; Kay 2006; Palmer 2009; Walseth 2006). The relationship between gender and disability is receiving increased attention as well (e.g., Anderson 2009; Lindermann and Cherney 2008). Several scholars have also used key concepts of theorist Pierre Bourdieu to demonstrate the complicated ways in which embodied gender, class and other social relations articulate within particular cultural "fields" or within specific institutional social positions (see especially Laberge 1995) including that of snowboarding (Thorpe 2009) and adventure racing (Kay and Laberge 2004).

In sum these diverse studies demonstrate the heterogeneity within the category of women while suggesting that complex articulations of power position women differently within social contexts. The scholarship on Black masculinity and sport (see for example, Carrington 1998), marginal masculinities (Connell 2002), and the representational politics of celebrity athletes like Michael Jordan (see for example, Andrews 2001; Andrews and Jackson 2001) likewise reveal a complex social order where all men do not share equally in power nor exert power over all women. This re-conceptualization allows for an understanding of identity, gender and power beyond the typical binary formulations endemic to Western thought: male/female; masculine/feminine; White/Black; and rich/poor.

Yet, this intersectional approach is not without limits. For example, some feminist theorists have noted that while intersectionality has been conceived to interrogate structures and subjectivities, it has been frequently applied solely on the micro level to investigate individual identities (Lewis 2009). The term also travels unevenly across disciplines and geographic spaces. One related concern is the extent to which a concept developed within the US with a particular emphasis on race is analytically useful in other national contexts and histories where an emphasis on ethnicity or religion might prove to be more analytically useful (Lewis 2009). This point likewise infers the need to expand what social relations are included in analyses. For example, scholars have infrequently applied an intersectional approach within the study of disability and/or within the study of whiteness and sport (but see Douglas 2005).

\section{Poststructuralism and Queer Movements}

\section{Poststructuralism}

While some scholars in the 1990s and 2000s remained dedicated to ideological critique, others were influenced by cultural studies' interdisciplinary impulse. They frequently looked outside of the typical social scientific and sport studies disciplines (e.g., sociology, psychology, women's studies and history) to expand their range of analytic tools and theoretical groundings. One result of this interdisciplinary quest was an embracing of poststructuralist perspectives as sport scholars gave greater attention to cultural narratives, the discursive circulation of meaning and production of knowledge imbued with power (Andrews 2000; Rail 1998). The application of Michael Foucault's writings allowed for yet another reconceptualization of key concepts including that of identity, power and sport.

Within many poststructuralist accounts identities such as gender or race are conceived of as effects of powersubject to historically produced discourses rather than as self-evident categories. Foucault developed this claim in relationship to sexuality suggesting that the categories of heterosexuality and homosexuality are examples of the workings of modern power closely associated with proliferating knowledges. That is, science, technology and a media-saturated culture work through discipline and surveillance to produce particular notions of the body as hierarchically divided into those who appear normal and deviant. This insight in turn offers a critique of Enlightenment understandings that suggest that people possess an essential core identity and active agency. In this way, the assumptions of this framework additionally provided an alternative ontology to the liberal humanist groundings still firmly embedded in much of the scholarship on women and sport.

Scholars using Foucauldian frameworks also think of power as productive, not necessarily repressive and as ubiquitous, connected to a multiplicity of discourses and knowledge formations. This orientation has encouraged its advocates to uncover the awesome influence of discourses in order to analyze "the production of sex/gender systems, identity effects, and bodies through practices associated with sport" (Cole and Birrell 1994, p. vii). Notable work in this regard includes the scholarship that has demonstrated the ways in which technologies of sporting regimes and the media articulate modern forms of power by encouraging the production of compliant gendered bodies through surveillance, discipline and normalization (Markula 2000; Shogun 1999). For example, the rules and dietary practices of elite women's gymnastics have required athletes to monitor themselves and obey the judge's gaze. This means that gymnasts distance themselves from any association with fatness and frailty thus producing skilled performances as well as culturally idealized feminine bodies: lean, acrobatic and fit (Johns and Johns 2000). Similar observations about disciplinary power have been applied to weight management techniques and women's rowing (Chapman 1997), and disabled athletes (Guthrie and Castelnuovo 2001).

Scholars have recently begun applying the later writings of Foucault to discuss "technologies of the self" or the ways in which particular sporting practices and associations "free 
the individual from the control of disciplinary power and consequently, lead to self transformation" (Markula 2003, p. 88). This suggests ways in which sporting discourses may be mobilized to achieve ethical self-care or awareness which can lead to, for example, a critical problematization of normative notions of femininity and ultimately social transformation (Markula 2003). For example, some overweight and self-described fat marathon runners articulated a critical awareness of the disciplining imperative of lean running bodies. The result is a consciously embracing of an alternative "Clydesdale" community that in turn challenged typical norms of femininity and ability (Chase 2008).

\section{Queering Sport Scholarship}

Comparable poststructuralist sensibilities have been discussed under the banner of queer theory. In a review essay delineating what queer theory might offer for sport scholars, King (2008b) identified additional features of queer theory including its commitments to antiidentitarianism and anti-normative politics. She also noted the recognition of contingency and multiplicity as hallmarks of this approach. Anti-identitarianism points out that incoherencies in identities such as sex or gender or sexuality means that such constructs are in "constant flux and shift over time, intermittently and sometimes regressively, and always in relation to the social, psychic, cultural, and economic relations in which they are introduced and enacted" (King 2008b, p. 423). Queer sensibilities have offered critiques of identity itself by exploring the preconditions that make some identities appear as stable and as "normal" and "abnormal." This dominant binary logic is structured and policed throughout elite sport, a notable example of which is the Olympic Games where female athletes have been subject to gender verification and sex testing procedures (Fausto-Sterling 2000). Instead of recognizing the existence of diverse bodies and gender performances as well as the incredible "variations in chromosomal, hormonal and morphological sex" (Sykes 2006 , p. 10), under the guise of maintaining an equal playing field, Olympic administrators continue to create policies that reflect anxieties about difference. Such policies, including the "Statement of the Stockholm Consensus on Sex Reassignment in Sport" seem to include transgender athletes into the Olympic games. Instead however, such policies continue to promote a conservative medicalized model where inclusion is only open to those who have completed sex reassignment surgery and hormone therapy allegedly to minimize gender related "advantages." Not only do such policies "prop up" static notions of identity but they additionally work to conceal local and non-Western understandings of bodies that are not captured by binary thinking (Sykes 2006).
The cultural work necessary to maintain these mythologies reveals that sex, gender and sexuality are not natural states of being, but are instead a "kind of doing, an incessant activity performed, in part, without one's knowing and without one's willing" (Butler 2004, p. 1). That is, the repeated performance of gender, sex and sexuality have created an illusion of naturalness when these are socially produced. To counter such practices queer theory remains anti-assimilationist in exploring the artificiality, effects and consequences of such articulations. Queer theorists instead "trouble and subvert such categories to create and defend spaces for nonnormative desires and practices" (King 2008 b, p. 422). This type of work allows "us to see the strangeness of our current state of knowledge and to question the way we think, and the conceptual tools which we use to think with" (Mills 2003, p. 64). The ultimate aim is offering an ethical response to dominant discourses by promoting the productive power of subjugated knowledges. In the case of the Olympic games this means critiquing such limiting policies as the Stockholm Consensus and instead embracing uncertainty and apprehension as well as the post-humanist possibilities offered through hybrid bodies and alterity (Sykes 2006).

Although Foucauldian and queer sensibilities have offered new ways for scholars to conceive of gender and sport, some critics have not embrace their central tenants fearful that such an embrace negates the importance of investigating material conditions. Others have suggested that queer and Foucauldian sport scholarship has not fully engaged other important discourses and thus frequently reifies whiteness and Western assumptions (King 2008b).

\section{Beyond the Present: Toward the Future}

In conclusion we reemphasize that this review is far from exhaustive and should be understood as offering an entry point for future engagement and revision. Our hope is that this review essay will open a dialogue within the pages of Sex Roles not only about the historical and contemporary study of gender and sport, but by extension, conversations about future work. Given the diversity of established and "yet to be named" approaches offering a definitive prediction about the future course of research is an impossible task. Still, a few emerging and under-researched topics are worthy of garnering additional attention.

We anticipate that intersectional analyses will only proliferate given the insights offered via conceptualizations of gender as an interacting force. Additionally as an analysis of the current state of the research suggests, there is a need to expand beyond typical gender, race and class analyses to incorporate the pervasive and powerful influence of whiteness. Also needed are more robust inves- 
tigations that acknowledge the ways gender interacts with such forces as those that produce disability, ethnicity, nationality and age. In a similar way, queer perspectives might better incorporate intersectional perspectives so as to more fully articulate important processes of racialization and globalization. Perhaps one way to achieve this goal is to embrace new frameworks. For example, there is a dearth of writings indebted to post-colonial understandings (but see Jamieson 2003) which would offer non-linear, nonexclusively Western perspectives to illuminate gender and sport scholarship. In addition, the movement away from privileging humanist understandings of the individual/self as rational have led an increasing number of scholars to explore the ways sport and gender identifications function within a psychoanalytic framework with a focus on unconscious fantasies, fears, drives and desires (see for example, Sykes 2001; Helstein 2003). Similar and emerging theorizing will undoubtedly open up fresh questions and new possibilities for rethinking gender and sport thus providing fruitful insights and more fodder for scholars commemorating future anniversaries in Sex Roles.

Open Access This article is distributed under the terms of the Creative Commons Attribution Noncommercial License which permits any noncommercial use, distribution, and reproduction in any medium, provided the original author(s) and source are credited.

\section{References}

Anderson, E. (2008). Being masculine is not about who you sleep with...: Heterosexual athletes contesting masculinity and the onetime rule of homosexuality. Sex Roles, 58, 104-115.

Anderson, D. (2009). Adolescent girls' involvement in sport: Implications for identity development. Journal of Sport and Social Issues, 33, 427-449.

Andrews, D. L. (2000). Posting up: French post-structuralism and the critical analysis of contemporary sporting cultures. In J. Coakley \& E. Dunning (Eds.), Handbook of sports studies (pp. 106-138). London: Sage.

Andrews, D. L. (Ed.). (2001). Michael Jordan, Inc.: Corporate sport, media culture and late modern America. Albany: State University of New York.

Andrews, D. L. (2006). Sport, commerce and culture: Essays on sport in late-capitalist America. New York: Peter Lang.

Andrews, D. L. (2008). Kinesiology's Inconvenient Truth and the physical cultural studies imperative. Quest, 60, 45-62.

Andrews, D. L., \& Jackson, S. (2001). Sport stars: The cultural politics or sporting celebrity. London: Routledge.

Banet-Weiser, S. (1999). Hoop dreams: Professional basketball and the politics of race and gender. Journal of Sport and Social Issues, 23, 403-420.

Birrell, S. (1988). Discourses on the gender/sport relationship: From women in sport to gender relations in sport. Exercise and Sport Science Reviews, 16, 459-502.

Birrell, S. (2000). Feminist theories for sport. In J. Coakley \& E. Dunning (Eds.), Handbook of sports studies (pp. 61-76). London: Sage.
Boutilier, M., \& SanGiovanni, C. (1983). The sporting woman. Champaign: Human Kinetics.

Boutilier, M., \& SanGiovanni, C. (1993). Politics, public policy and Title IX: Some limitations of liberal feminism. In S. Birrell \& C. Cole (Eds.), Women, sport and culture (pp. 97-110). Champaign: Human Kinetics.

Burton, L., Barr, C., Fink, J., \& Bruening, J. (2009). "Think athletic director, think masculine?": Examination of the gender typing of managerial subroles within athletic administration positions. Sex Roles, 61, 416-426.

Butler, J. (2004). Undoing gender. New York: Routledge.

Cahn, S. (1994). Coming on strong: Gender and sexuality in twentieth century women's sport. New York: Free.

Carrington, B. (1998). Sport, masculinity, and Black cultural resistance. Journal of Sport and Social Issues, 22, 275-298.

Caudwell, J. C. (2006). Sport, sexualities and queer/theory. London: Routledge.

Chapman, G. (1997). Making weight: Lightweight rowing, technologies of power, and technologies of the self. Sociology of Sport Journal, 14, 205-223.

Chase, L. (2008). Running big: Clydesdale runners and technologies of the body. Sociology of Sport Journal, 25, 130-147.

Claringbould, I., \& Knoppers, A. (2007). Finding a 'normal' woman: Selection processes for board membership. Sex Roles, 56, 495-507.

Claringbould, I., \& Knoppers, A. (2008). Doing and undoing gender in sport governance. Sex Roles, 58, 81-92.

Claringbould, I., Knoppers, A., \& Elling, A. (2004). Exclusionary practices in sport journalism. Sex Roles, 51, 709-718.

Cole, C. L., \& Birrell, S. (1994). Preface. In S. Birrell \& C. L. Cole (Eds.), Women, sport and culture (pp. vi-viii). Champaign: Human Kinetics.

Colker, R., \& Widom, C. S. (1980). Correlates of female athletic participation: Masculinity, femininity, self-esteem, and attitudes toward women. Sex Roles, 6, 47-58.

Collins, P. H. (1990). Black feminist thought: Knowledge, consciousness, and the politics of empowerment. Boston: Unwin Hyman.

Connell, R. (1995). Masculinities. Berkeley, CA: University of California Press.

Connell, R. W. (1987). Gender and power. Stanford: Stanford University Press.

Connell, R. W. (2002). Masculinities and globalization. In H. Wroth, A. Paris, \& L. Allen (Eds.), The life of Brian: Masculinities, sexualities and health in New Zealand (pp. 27-42). Dunedin: University of Otago.

Connell, R. W. (2005). Masculinities (2nd ed.). Berkeley: University of California Press.

Corbett, D., \& Johnson, W. (1993). The African American female in college sport: Racism and sexism. In D. Brooks \& R. C. Althouse (Eds.), Racism in college athletics: The African American athlete's experience (pp. 179-204). Morgantown: Fitness Technologies.

Coulomb-Cabagno, G., Rascle, O., \& Souchon, N. (2005). Players' gender and male referees' decisions about aggression in French soccer: A preliminary study. Sex Roles, 52, 547-553.

Crenshaw, K. W. (1991). Mapping the margins: Intersectionality, identity politics, and violence against women of color. Stanford Law Review, 6, 1241-1299.

Croxton, J., \& Klonsky, B. (1982). Sex differences in causal attributions for success and failure in real and hypothetical sport settings. Sex Roles, 8, 399-409.

Cunningham, G., Sagas, M., Sartore, M., Amsden, M., \& Schellhase, A. (2004). Gender representation in the NCAA News: Is the glass half full or half empty? Sex Roles, 50, 861-870.

Cunningham, G., Doherty, A., \& Gregg, M. (2007). Using social cognitive career theory to understand head coaching intentions among assistant coaches of women's teams. Sex Roles, 56, 365-372. 
Cunningham, G., Fink, J., \& Kenix, L. (2008). Choosing an endorser for a women's sporting event: The interaction of attractiveness and expertise. Sex Roles, 58, 371-378.

De Bruin, A., Woertman, E., Bakker, F., \& Oudejans, R. (2009). Weight-related sport motives and girls' body image, weight control behaviors, and self-esteem. Sex Roles, 60, 628-641.

Desertrain, G. S., \& Weiss, M. (1988). Being female and athletic: A cause for conflict? Sex Roles, 18, 567-582.

Douglas, D. D. (2005). Venus, Serena and the Women's Tennis Association: When and where race enters. Sociology of Sport Journal, 22, 256-282.

Duncan, M. C. (1990). Sports photographs and sexual difference: Images of women and men in the 1984 and 1988 Olympic Games. Sociology of Sport Journal, 7, 20-40.

Duncan, M. C. (2006). Gender warriors in sport: Women and the media. In A. Rainey \& J. Bryant (Eds.), Handbook of sports and media (pp. 231-252). Philadelphia: Erlbaum.

Fausto-Sterling, A. (2000). Sexing the body: Gender politics and the construction of sexuality. New York: Basic.

Felshin, J. (1975). The triple option....for women in women's sport. Quest, 21, 36-40.

Fielding-Lloyd, B., \& Meân, L. (2008). Standards and separatism: The discursive construction of gender in English soccer coach education. Sex Roles, 58, 24-39.

Franzoi, S., \& Kleiber, J. (2007). Body use and reference group impact: With whom do we compare our bodies? Sex Roles, 56, 205-214.

Frieze, I. H., \& Dittrich, S. (2008). Sex Roles: An international journal. Sex Roles, 58, 751.

Frieze, I. H., \& Dittrich, S. (2010). Sex Roles is 35! Sex Roles, 62, 1.

Greendorfer, S. L. (1978a). Social class influence on female sport involvement. Sex Roles, 4, 619-625.

Greendorfer, S. (1978b). Socialization into sport. In C. Olgesby (Ed.), Women and sport: From myth to reality (pp. 15-40). Philadelphia: Lea \& Febiger.

Greenleaf, C., Boyer, E., \& Petrie, T. (2009). High school sport participation and subsequent psychological well-being and physical activity: The mediating influences of body image, physical competence, and instrumentality. Sex Roles, 61, 714-726.

Griffin, P. (1998). Strong women, deep closets: Lesbians and homophobia in sport. Champaign: Human Kinetics.

Guthrie, S. R., \& Castelnuovo, S. (2001). Disability management among women with physical impairments: The contributions of physical activity. Sociology of Sport Journal, 18, 5-20.

Hall, M. A. (1988). The discourse of gender and sport: From femininity to feminism. Sociology of Sport Journal, 5, 330-340.

Hall, M. A. (1996). Feminism and sporting bodies: Essays in theory and practice. Champaign: Human Kinetics.

Hardin, M., Lynn, S., \& Walsdorf, K. (2005). Challenge and conformity on "contested terrain": Images of women in four women's sport/fitness magazines. Sex Roles, 53, 105-117.

Hargreaves, J. A. (1994). Sporting females: Critical issues in the history and the sociology of women's sport. London: Routledge.

Hargreaves, J. A. (2000). Heroines of sport: The politics of difference and identity. London: Routledge.

Harrison, L., \& Lynch, A. (2005). Social role theory and the perceived gender role orientation of athletes. Sex Roles, 52, 227-236.

Hart, M. (1972). On being female in sport. In M. Hart (Ed.), Sport in the sociocultural process (pp. 291-301). Dubuque: William C. Brown.

Hebl, M., Giuliano, T., King, E., Knight, J., Shapiro, J., Skorinko, J., et al. (2004). Paying the way: The ticket to gender equality in sports. Sex Roles, 51, 227-235.

Helstein, M. (2003). That's who I want to be: The politics and production of desire within Nike advertising to women. Journal of Sport and Social Issues, 27, 276-292.

Hendy, H., \& Boyer, B. (1993). Gender differences in attributions for triathlon performance. Sex Roles, 29, 527-543.
Hoeber, L. (2007). Exploring the gap between meanings and practices of gender equity in a sports organization. Gender, Work and Organization, 14, 259-277.

Hoeber, L. (2008). Gender equity for athletes: Multiple understandings of an organizational value. Sex Roles, 58, 58-71.

Hoferek, M., \& Hanick, P. (1985). Woman and athlete: Toward role consistency. Sex Roles, 12, 687-695.

Jamieson, K. (1998). Reading Nancy Lopez: Decoding representations of race, class, and sexuality. Sociology of Sport Journal, $15,343-358$.

Jamieson, K. (2003). Occupying a middle space: Toward a mestiza sport studies. Sociology of Sport Journal, 20, 1-16.

Jamieson, K. (2005). "All my hopes and dreams": Families, schools and subjectivities in collegiate softball. Journal of Sport and Social Issues, 29, 133-147.

Johns, D. P., \& Johns, J. S. (2000). Surveillance, subjectivism and technologies of power: An analysis of the discursive power of high performance sport. International Review for the Sociology of Sport, 35(2), 219-234.

Kane, M. J. (1995). Resistance/transformation of the oppositional binary: Exposing sport as a continuum. Journal of Sport and Social Issues, 19, 191-218.

Kanter, R. M. (1977). Men and women of the corporation. New York: Basic Books.

Kay, T. (2006). Daughters of Islam: Family influences on Muslim young women's participation in sport. International Review for the Sociology of Sport, 41, 357-373.

Kay, J., \& Laberge, S. (2004). "Mandatory equipment": Women in adventure racing. In B. Wheaton (Ed.), Understanding lifestyle sports: Consumption, identity and difference (pp. 154-174). New York: Routledge.

King, S. (2008a). Virtually normal: Mark Bingham, the war on terror and the sexual politics of sport. Journal of Sport and Social Issues, 33, 5-24.

King, S. (2008b). What's queer about (queer) sport sociology now? A review essay. Sociology of Sport Journal, 25, 419-442.

King, S., \& McDonald, M. G. (2007). (Post)identity and sport: Introduction and overview. Sociology of Sport Journal, 24, 1-19.

Kleiber, D., \& Hemmer, J. (1981). Sex differences in the relationship of locus of control and recreational sport participation. Sex Roles, 7, 801-810.

Klomsten, A. T., Skaalvik, E., \& Espnes, G. (2004). Physical selfconcept and sports: Do gender differences still exist? Sex Roles, 50, 119-127.

Klomsten, A. T., Marsh, H., \& Skaalvik, E. (2005). Adolescents' perceptions of masculine and feminine values in sport and physical education: A study of gender differences. Sex Roles, 52, 625-636.

Knoppers, A. (1980). Androgyny: Another look. Quest, 32, 184-191.

Knoppers, A., \& Anthonissen, A. (2008). Gendered managerial discourses in sport organizations: Multiplicity and complexity. Sex Roles, 58, 93-103.

Koca, C., Așçi, F. H., \& Kirazcr, S. (2005). Gender role orientation of athletes and nonathletes in a patriarchal society: A study in Turkey. Sex Roles, 52, 217-225.

Koivula, N. (1999). Gender stereotyping in televised media sport coverage. Sex Roles, 41, 589-604.

Krane, V., Choi, P., Baird, S., Aimar, C., \& Kauer, K. (2004). Living the paradox: Female athletes negotiate femininity and muscularity. Sex Roles, 50, 315-329.

Laberge, S. (1995). Toward an interpretation of gender into Bourdieu's concept of cultural capital. Sociology of Sport Journal, 12, 132-147.

Lenskyj, H. (1986). Out of bounds Women, sport and sexuality. Toronto: Women's.

Lewis, G. (2009). Celebrating intersectionality? Debates on a multifaceted concept in gender studies: Themes from a conference. European Journal of Women's Studies, 16, 203-210. 
Linderman, K., \& Cherney, L. (2008). Communicating in and through "Murderball": Masculinity and disability in wheelchair rugby. Western Journal of Communication, 72, 107-125.

Markula, P. (2000). "I gotta do the marathon": Women running as a truth-game. Aethlon, 18, 89-106.

Markula, P. (2003). Technologies of the self: Sport, feminism and Foucault. Sociology of Sport Journal, 20, 87-107.

Marsh, H., \& Jackson, S. (1986). Multidimensional self-concepts, masculinity, and femininity as a function of women's involvement in athletics. Sex Roles, 15, 391-415.

Matteo, S. (1986). The effect of sex and gender-schematic processing on sport participation. Sex Roles, 15, 417-432.

Matteo, S. (1988). The effect of gender-schematic processing on decisions about sex-inappropriate sport behavior. Sex Roles, 18, 41-58.

McDonald, M. G. (2006). Thinking through power in sport and sport media scholarship. In A. Rainey \& J. Bryant (Eds.), Handbook of sports and media (pp. 231-252). Philadelphia: Erlbaum.

McDowell, J., \& Cunningham, G. (2008). Reactions to physical contact among coaches and players: The influence of coach sex, player sex, and attitudes toward women. Sex Roles, 58, 761767.

Messner, M. (1988). Sport and male domination: The female athlete as contested ideological terrain. Sociology of Sport Journal, 5, 197-211.

Messner, M. A. (1990). Masculinities and athletic careers: Bonding and status differences. In M. A. Messner \& D. Sabo (Eds.), Sport, men and the gender order: Critical feminist perspectives (pp. 97108). Champaign: Human Kinetics.

Messner, M. A. (1992). Power at play: Sports and the problem of masculinity. Boston: Beacon.

Messner, M. (2009). It's all for the kids: Gender, families, and youth sports. Berkeley: University of California Press.

Miller, T. (1998). Commodifying the male body: Problematizing "hegemonic masculinity"? Journal of Sport and Social Issues, $22,431-447$.

Miller, J., \& Levy, G. (1996). Gender role conflict, gender-typed characteristics, self concepts, and sport socialization in female athletes and nonathletes. Sex Roles, 35, 111-122.

Mills, S. (2003). Michael Foucault. London: Routledge.

Palmer, C. (2009). Soccer and the politics of identity for young Muslim refugee women in South Australia. Soccer \& Society, 10, 27-38.

Parks, J., \& Roberton, M. (1998). Influence of age, gender, and context on attitudes toward sexist/nonsexist language: Is sport a special case? Sex Roles, 38, 477-494.

Parks, J., \& Roberton, M. (2000). Development and validation of an instrument to measure attitudes toward sexist/nonsexist language. Sex Roles, 42, 415-438.

Rail, G. (1998). Seismography of the postmodern condition: Three theses on the implosion of sport. In G. Rail (Ed.), Sport and postmodern times (pp. 143-161). Albany: State University of New York.

Rao, V. V. P., \& Overman, S. (1984). Sex-role perceptions among Black female athletes and nonathletes. Sex Roles, 11, 601-614.

Roper, E., \& Halloran, E. (2007). Attitudes toward gay men and lesbians among heterosexual male and female student-athletes. Sex Roles, 5, 919-928.

Ross, S., \& Shinew, K. (2008). Perspectives of women college athletes on sport and gender. Sex Roles, 58, 40-57.

Russell, K. (2004). On versus off the pitch: The transiency of body satisfaction among female rugby players, cricketers, and netballers. Sex Roles, 51, 561-574.

Sagas, M., \& Cunningham, G. (2004). Does having "the right stuff" matter? Gender differences in the determinants of career success among intercollegiate athletic administrators. Sex Roles, 50, 411-421.

Sartore, M., \& Cunningham, G. (2009). Gender, sexual prejudice and sport participation: Implications for sexual minorities. Sex Roles, $60,100-113$.
Schrack-Walters, A., O’Donnell, K., \& Wardlow, D. (2009). Deconstructing the myth of the monolithic male athlete: A qualitative study of men's participation in athletics. Sex Roles, 60, 81-99.

Scraton, S., \& Flintoff, A. (2002). Sport feminism: The contribution of feminist thought to our understandings of gender and sport. In S. Scraton \& A. Flintoff (Eds.), Gender and sport: A reader (pp. 30-46). New York \& London: Routledge.

Scraton, S., Caudwell, J., \& Holland, S. (2005). "Bend it like Patel": Centering, "race", ethnicity and gender in feminist analysis of women's football in England. International Review for the Sociology of Sport, 4, 71-88.

Shaffer, D., \& Wittes, E. (2006). Women's precollege sports participation, enjoyment of sports, and self-esteem. Sex Roles, 55, 225-232.

Shaw, S., \& Allen, J. (2009). The experiences of high performance women coaches: A case study of two regional sport organizations. Sports Management Review, 12, 217-228.

Shogun, D. (1999). The making of high-performance athletes: Discipline, diversity and ethics. Toronto: University of Toronto.

Smiler, A. (2004). Thirty years after the discovery of gender: Psychological concepts and measures of masculinity. Sex Roles, 50, 15-26.

Sykes, H. (2001). Of gods, money and muscle: Resurgent homophobias and the narcissism of minority differences in sport. Psychoanalysis and Contemporary Thought, 24, 203-225.

Sykes, H. (2006). Transexual and transgender politics in sport. Women in Sport and Physical Activity Journal, 15, 3-13.

Theberge, N. (1985). Toward a feminist alternative to sport as a male preserve. Quest, 37, 193-202.

Theberge, N. (2000). Gender and sport. In J. Coakley \& E. Dunning (Eds.), Handbook of sports studies (pp. 322-333). London: Sage.

Thorpe, H. (2009). Bourdieu, feminism and female physical culture: Gender reflexivity and the habitus-field complex. Sociology of Sport Journal, 26, 491-516.

Trujillo, N. (1995). Machines, missiles, and men: Images of the male body on ABC's Monday Night Football. Sociology of Sport Journal, 12, 403-423.

Van Ingen, C. (2003). Geographies of gender, sexuality and race: Reframing the focus on space in sport studies scholarship. International Review for the Sociology of Sport, 38, 201-216.

Von der Lippe, G. (2002). Media image: Sport, gender and national identity in five European countries. International Review for the Sociology of Sport, 17, 371-395.

Walseth, K. (2006). Young Muslim women and sport: The impact of identity work. Leisure Studies, 25, 75-94.

Weiss, M., \& Barber, H. (1995). Socialization influences of collegiate female athletes: A tale of two decades. Sex Roles, 33, 129-140.

Whisenant, W. (2003). How women have fared as interscholastic athletic administrators since the passage of Title IX. Sex Roles, 49, 179-184.

Whisenant, W. (2008). Sustaining male dominance in interscholastic athletics: A case of homologous reproduction...or not? Sex Roles, 58, 768-775.

Whisenant, W., Miller, J., \& Pedersen, P. (2005). Systemic barriers in athletic administration: An analysis of job descriptions for interscholastic athletic directors. Sex Roles, 53, 911-918.

Willis, P. (1982). Women in sport in ideology. In J. Hargreaves (Ed.), Sport, culture and ideology (pp. 117-135). London: Routledge.

Wrisberg, C., Draper, M. V., \& Everett, J. (1988). Sex role orientations of male and female collegiate athletes from selected individual and team sports. Sex Roles, 19, 81-90.

Young, J., \& Bursik, K. (2000). Identity development and life plan maturity: A comparison of women athletes and nonathletes. Sex Roles, 43, 241-254.

Young, K., \& White, P. (2000). Researching sports injury: Reconstructing dangerous masculinities. In J. McKay \& D. Sabo (Eds.), Masculinities, gender relations and sport (pp. 108-126). Thousand Oaks: Sage. 